\section{Technology for the drosophilist}

\section{Michael Ashburner}

Drosophila: A Practical Approach. Edited by D. B. Roberts. IRL Press:1986. Pp. 295. Hbk £26, \$47; pbk£16.50, \$30.

THE attraction of Drosophila to wine is noted in the earliest reference I know to this fly - John Milton's Paradise Regained (1671). Despite more recent advances in science, the molecular basis of the phenomenon is still unknown. Nevertheless, Drosophila is used as a "model" organism for the study of olfaction and indeed for almost every other problem in biology. The reason is that we know more about the biology of this fly, in all of its aspects, than of any other respectable eukaryote (n.b. Drosophila eats yeast for breakfast, lunch and dinner). Yet this very knowledge of Drosophila, and the language of Drosophila geneticists, must have intimidated as many biologists from working with the creature as it has attracted. That may be just as well; the days when one could know everyone in the field are, alas, past.

Much of the excitement of modern research with Drosophila is due to the activi-

This is a great book, and an exciting book... readable, worth reading and enlightening.

Sir Karl Popper

\section{Cosmology, Physics \& Philosophy by Prof Ben Gal-Or}

"a master piece... any good library must have a copy of this classical work."

Ind. J. Phys.

“... a tour de force... will be widely read and appreciated... a magnificent and sustained piece of work!"

\section{Sir Alan Cottrell}

... remarkable... challenging... Am. J. Phys.

\section{2nd Printing}

Springer-Verlag

175 5th Ave., N.Y., 10010 ties of converts to the field, and David Roberts, the editor of this book, is a particularly welcome one. Drosophila: A Practical Approach is a valuable introduction to some of the technologies used in this industry, and as such fills an empty niche. Not that it is complete (a fact that Roberts, in his preface, tries to convince us is a virtue), most conspicuously so in the absence of a chapter on the more sophisticated aspects of Drosophila genetics and chromosome mechanics. Those who turn to Chapter 10 for the "details of ring chromosomes" (p. 11) will be sorely disappointed. If the omission of an account of "serious" genetics was planned, then that was an error of judgement; if not, the recalcitrant contributors should be publicly identified and dealt with.

Despite this, the book will be an invaluable addition to a fly-pusher's working library. I don't agree with everything in it but there are relatively few places where it will seriously mislead the novice. Roberts's own chapter is a simple, readable introduction, and those that follow - on mutagenesis, P-M mutagenesis, in situ hybridization to both chromosomes and tissues, looking at embryos, transformation and cell surface antigens - will be of value to all but the most desk-bound drosophilist. They contain much that is new, or at least much that has not before been committed to print. Two "molecular" chapters, Pirrotta on cloning and Jowett on the preparation of nucleic acids, are also of interest. They describe the tricks used for working with the DNA and RNA of flies, sensibly not attempting to replace "Maniatis". Pirrotta's chapter includes a detailed consideration of chromosome microdissection and microcloning; this may not obviate the necessity of travel to foreign parts before attempting the technique, but will certainly give the reader a very good idea of what is involved and help him write his travel grant proposal.

By and large, the editorial efforts to make the text easily readable have been successful. Some of the flavour of the drosophilist's art can be obtained from reading the chapter by Lawrence and others on making mosaics. But I will not spoil the reader's fun in discovering what "strump hapely" is, why flies to be mounted should be neither shaken nor stirred or why Gary's mountant is so magic.

Roberts has finished what many have begun, to compile a convenient laboratory manual for Drosophila. If you already work with Drosophila buy this book and read it; don't think that you will know it all, you won't. If you are planning to work with Drosophila then buy this book. If you have vowed never to work with Drosophila then still buy this book. It will help show how misguided you have been.

Michael Ashburner is in the Department of Genetics, University of Cambridge, Downing Street, Cambridge CB2 $3 E H, U K$.

\section{Fruits of NMR}

\section{E. R. Andrew}

Nuclear Magnetic Resonance Imaging in Medicine and Biology. By Peter G. Morris. Clarendon:1986. Pp.388. £35, \$59.

IT Is just 50 years since Gorter's first attempt to detect nuclear magnetic resonance (NMR), and 40 years since its successful detection in bulk matter by Bloch and Purcell and their respective colleagues. Over the years NMR progressed from being a valuable method of investigation in physics to become an indispensable spectroscopic technique of chemistry, biochemistry and other disciplines.

Then, in 1973, Lauterbur showed that with the addition of field gradients images of heterogeneous structured objects could be obtained by NMR and gave a practical demonstration. By the late 1970 s several laboratories had obtained images of sections of the human body, and medical instrument manufacturers took over. Shortly afterwards clinical assessment had begun and magnetic resonance imaging is now an accepted modality in the radiologist's armoury of investigative techniques. It gives images of almost equal quality to those from computed tomography $\mathrm{X}$-ray scanning, often with better contrast, and although it is slightly more expensive it is inherently much safer because no ionizing radiation is involved. Further, it has the great merit of scanning in transverse, sagittal and coronal orientations with equal ease.

Many people, from radiologists and other clinicians to hospital physicists and instrument designers, need to learn about the technique and Dr Morris has provided an excellent introduction. His pleasant clear style gives a most readable entry to the subject. He lays a firm foundation of the principles of NMR and of the various imaging techniques, including those now superseded. He covers in detail the design of large magnets and all other hardware components and provides a substantial account of applications of NMR imaging in biology and medicine, including also a section on in vivo NMR spectroscopy. Although glossy paper is not used for the images they have reproduced reasonably well.

The manuscript was apparently completed in 1984, and in this fast-moving field we may look forward to fresh editions to keep up with the subject. But as it stands Dr Morris's book will be an essential point of reference for everyone working in the field or needing to know something about it.

$E . R$. Andrew is Research Professor in the Department of Physics, University of Florida, Gainesville, Florida 32611, USA. 